\title{
Knowledge of Surgical Informed Consent and Associated Factors among Patients Undergone Obstetric and Gynecologic Surgery at Jimma Medical Center, Jimma, Oromia Region, Ethiopia, 2020. An Institutional Based Cross-Sectional Study.
}

Belete Fenta Kebede ( $\sim$ belete121wy@gmail.co)

Jimma Institute of Health Sciences: Jimma University

Tsegaw Biazin Tesfaye

Jimma Institute of Health Sciences: Jimma University

Aynalem Yetwale Hiwot

Jimma Institute of Health Sciences: Jimma University

Research

Keywords: Knowledge, Informed Consent, surgical patients, Jimma, Ethiopia

Posted Date: June 11th, 2021

DOI: https://doi.org/10.21203/rs.3.rs-607203/v1

License: (c) (1) This work is licensed under a Creative Commons Attribution 4.0 International License.

Read Full License 


\section{Abstract}

Introduction: The practice of informed consent before any surgical procedure should form the fundamental element that serves to protect both patient and surgeon from prosecution. Several factors can affect the process of surgical informed consent. Knowledge towards surgical informed consent is one important factor. It is worth mentioning that patients' understanding of the information provided in the consent form is a prerequisite for obtaining valid informed consent, otherwise, it will be only symbolic. The study aimed to assess knowledge of surgical informed consent and associated factors among patients who undergone obstetric and gynecologic surgery at Jimma Medical Center, Jimma, Oromia Region, Ethiopia

Methodology: Institutional based crossectional study was conducted among systematically selected women undergo obstetrics and gynecologic surgery in Jimmy medical center from April 1 to May 30, 2020. The collected data were coded, entered into Epi data version 3.1, and analyzed using SPSS version 25. Bivariate and multivariate regression was carried out to determine the association between an outcome variable and an independent variable. Tables, pie -charts, and texts were used to report the result.

Results: This study revealed that the mean age of the respondents was $29.5 \pm 3.5$ years and the majority of them (83.3\%) were married. The respondents had significantly poor overall knowledge of surgical informed consent 77.2 \%( 95\% Cl: 72.8-81.2).Patient educational status (AOR: 1.22 (95\% Cl: 1.1-2.47), satisfaction level (AOR: 1.823(95\% Cl: 1.061-3.134).and patient- provider relation-ship (AOR: $0.472(95 \% \mathrm{Cl}$ : 0.271-0.822) were associated with knowledge of surgical informed consent.

Conclusion: in this study, the overall level of knowledge regarding surgical informed consent was significantly poor than the other national and international figures. Patient Education, satisfaction, and patient-provider relation-ship were associated with knowledge of surgical informed consent. Health care providers should provide adequate information before surgery to improve patients' knowledge regarding surgical informed consent and provide adequate input on ways to improve the consent process to make it better suited to fit the needs of all patients.

\section{Introduction}

The concept of informed consent is an important aspect of biomedical ethics, which knows the autonomy of patients in healthcare service providers and patient relationships (1). It is an ethical obligation of health care professionals to uphold patients' autonomy and let them decide on the proposed medical, surgical, or other health care and research interventions(2). The consent is generally obtained in written but, in some cases, it may be verbal especially for the non-invasive and relatively nonrisky interventions like vital-sign and pelvic examination, Breast Examination to obstetrics and gynecologic client $(1,3)$ 
Several factors may affect informed consent, including the patient's competence, provision of limited information, unsuccessful communication between patients and professionals, the hospital environment itself, privacy issues, and inadequate time $(1,2,4)$. The informed consent process is vital to patients; however, patients vary in their views of its purpose with the dominant view being enabling patients' selfdecision-making (5).

Women need consistent and adequate information for consent and should undergo it with proper knowledge, awareness, and confidence (6). Lack of patient's knowledge on surgical informed consent increases the likelihood of a patient safety incident, patient anxiety, and result in postoperative dissatisfaction(7). Providing educational programs to patients and junior physicians is mandatory to fill the knowledge gaps and improve the quality of the informed consent process(8).

According to cross- sectional study conducted among surgical patients at the hospital of Istanbul University 39 (38.1\%) declared that they have not sufficient knowledge on the subject of consent(9).based on the crossectional descriptive study conducted in Brazil(10)evidenced that $44.7 \%$ of participants had full understanding regarding free and informed consent.

According to the crossectional study conducted on patients awareness level regarding the informed consent India, Overall the level of understanding was poor in $17 \%$, unsatisfactory in $33 \%$, satisfactory in $32 \%$, and good in $18 \%$ of the patients and the level of understanding was significantly associated with educational level (11).

The Crossectional study conducted among obstetrics and gynecologic patients in Kano, Nigeria revealed that Awareness and knowledge of consent were high which accounts significant percentage (97.5\%) (12). The descriptive correlational study conducted among surgical patients at Rwanda military referral hospital revealed that Eighty-three percent (83\%) had low knowledge of surgical informed consent (7).

A Crossectional study conducted among physicians and patients at Cairo revealed that (49.4\%) physicians reported that they informed patients about their medical condition in details, while $38.9 \%$ of patients reported that they have been informed about their medical condition in details(8). In Ethiopia, Based on a crossectional study done among adults who underwent surgery at St. Paul's Hospital Millennium Medical College, only 40 (10.5\%) respondents had a good level of knowledge and had an association with educational level and residency area (13). Currently, the importance of obtaining consent before any surgery is well established altogether hospitals. However, the practice and understanding of the consent process aren't uniform among health professionals and patients (14). Although many studies show that surgical, informed consent leads to positive postoperative outcomes $(7,11)$ However, there is less existing literature focused on the patient's level of knowledge towards the surgical informed consent and associated factors to the patient's knowledge in Ethiopia. Therefore, this study aimed to assess knowledge towards informed consent and factors associated with knowledge among patients before their obstetrics and gynecologic surgery and setting recommendations to improve patient's level of knowledge, in Jimma medical center. 
This study will be significant in midwifery, obstetrics, and gynecologic clinical practice because it will improve the surgical informed consent process by highlighting the patient and the health care provider's roles and responsibilities in the informed consent process.

In education, this study will help midwifery students, anesthesia students, clinical nurses, and other health care providers to learn evidence-based practice in surgical procedures and to recognize surgical informed consent as an autonomous action from the patient and helps to improve the patient's knowledge towards the informed surgical consent.

In research, the data of this study will be used by other health researchers to conduct further studies using this study, as a source of evidence therefore, the cost of their study will be reduced. For guideline development group and administration, this study will help to establish the guideline on informed consent for surgery and to establish surgical informed consent policy, and adhere to good clinical practice.

\section{Methods And Materials}

\section{Study area and period}

This study was conducted in Jimma Medical Center, Jimma town, Ethiopia. Jimma town is situated about 354 kilometers away from Addis Ababa; the capital city of Ethiopia. Around 1,461 and 900 patients were undergone obstetric and gynecological- related surgery within the past six months respectively (the previous 6- month report) and the study period was from April 1 to May 30, 2020.

\section{Study design}

Institutional based cross-sectional study was conducted among patients admitted to the gynecology and obstetrics ward of Jimma medical center, Jimma, Ethiopia.

\section{Population}

\section{Source population}

All women who undergone obstetrics and gynecologic surgeries in Jimma medical center were the source population.

\section{Study population}

All Selected women who undergone obstetrics and gynecologic surgeries were the study population of the study.

\section{Eligibility criteria \\ Inclusion criteria}


All women with age 18 years old and above, who undergo obstetrics and gynecologic surgery at Jimma medical center during the study period, and consent for the study were included.

\section{Exclusion criteria}

Patients who were undergoing surgeries but who were considered too ill to consent for surgery, for instance, patients who are not fully conscious at the time of data collection were excluded.

\section{Sample size determination}

The sample size was determined using single population proportion formula by considering

$50 \%$ proportion $(P)$, because of no study conducted previously in Ethiopia; with $95 \%$ confidence interval (1.96); $a=0.05$ and $5 \%$ marginal of error.

$=(1.96) 2 * 0.5(1-0.5) /(0.05) 2=0.954 / 0.0025=384$.

After adding a non-response rate of $5 \%(19.2 \sim 20)$, the final sample size was 404

\section{Sampling techniques and procedure}

A Systematic sampling technique was conducted to select study participants from 798 total two-month surgical cases after determining the interval (Kth). The k-interval was determined by dividing the total two-month surgical case (798) the final sample size (404) that was given approximately two. The first study participant was selected by lottery method using their registration serial number then the rest were selected every interval from the registration book until the final sample size reached.

\section{Variables}

\section{Dependent variable (outcome variable)}

- Knowledge towards surgical informed consent

\section{Independent variables}

- Social-demographic characteristics: Age, educational status, occupation, marital status, and residence

- Patient- related factors: Parity, knowledge, type of surgery, and previous surgery.

- Health care providers related factors: Patient to health care provider relationship

- Service- related factors: the language of the written consent form, profession who request informed consent, the timing of consent, time taken to provide informed consent, and time taken to decision making

\section{Operational definitions}

Informed consent: the practices of providing the necessary information that allows the informed consent to make autonomous authorization. 
Knowledge on surgical informed consent: In the context of this study, knowledge about surgical informed consent if women answered knowledge questions with the above mean score consider good knowledge otherwise having poor knowledge (7).

Patient to doctor relationship: The patient to doctor relationship can be seen as the perception of the patient concerning the caring shown by the doctor and the attitude and behavior of the doctor towards the patient. The PDRQ contains nine items with a yes/no option.

\section{Data collection tools and procedures}

The data was collected using pretested; structured closed-ended interviewer- administered questionnaire and document review (Type of surgery and time of consent). The questioner had e six parts. The first part was about socio-demographic consist of 8 items, the second part deals with the patient-related factors consist 7 items, the third one about service- related factors consist 8 items, the fourth part about recommending component of informed consent consist 13 items, the fifth part deal with patient to healthcare provider relationship consist 9 items and the last sixth part deal about patients' knowledge towards surgical informed consent. The tool was designed in English and Oromifa languages. Two BSc and one MSc nurses were recruited as data collectors and supervisors respectively.

\section{Data quality assurance}

In order to ensure the quality of data, different measures were undertaken. The questionnaire was initially prepared in English then translated to the local language (Afaan Oromo), then translated back to English. Before actual data collection, a pretest was conducted on $5 \%$ of the total samples in another setting. After obtaining it appropriate corrections were made before using it for the main study. One day of training was given for the data collectors. During the data collection period, the data were checked for completeness and consistency of information by the principal investigator. Any error, ambiguity, incompleteness, or other problems were addressed through communication with data collectors before the beginning of the next day's activities.

\section{Data processing, analysis, and presentation}

The collected data ware coded and entered into Epi data 3.1 and exported to SPSS version 25. Hosmer and Lemeshow test was done to confirm the model fitness, and the model has been fitted. Bivariate and Multivariable analyze were done between knowledge of surgical informed consent and independent variables. In bivariate logistic regression, the variables which had a p-value less than 0.25 was considered as candidate variable for multivariable logistic analysis. In multivariable analysis, those variables which had a p-value less than 0.05 were considered statistically significant with the outcome variable. The finding of the data was presented by using text, tables, figures, and graphs. 


\section{Results}

This study used to measure the level of knowledge towards surgical informed concept among participants to their surgical procedure, from the total sample of four hundred four (404) women, three hundred seventy- two (372) of them were agreed to involve in the study and gave a response rate of $92.1 \%$.

\section{Socio-demographic characteristics}

Three hundred seventy- two (372) patients were recruited for the study. In this study, the mean age of the respondents was $29.5 \pm 3.5$ years. The Majority of the respondents (83.3\%) were married. Two hundred ninety-one respondents were literate. (Table 1).

Table 1

Socio-demographic characteristics at Jimma medical center, Jimma, Ethiopia, 2020

\begin{tabular}{|c|c|c|c|}
\hline Variable & Classification & Frequency & Percent \\
\hline \multirow[t]{3}{*}{ Age (years) } & $<35$ & 324 & 89.1 \\
\hline & $\geq 35$ & 48 & 12.9 \\
\hline & Mean and SD & $29.5 \pm 3.5$ & \\
\hline \multirow[t]{2}{*}{ Education status } & Illiterate & 81 & 21.8 \\
\hline & Literate & 291 & 78.2 \\
\hline \multirow[t]{2}{*}{ Marital status } & Single & 62 & 16.6 \\
\hline & Married & 310 & 83.3 \\
\hline \multirow[t]{6}{*}{ Occupation } & Housewife & 168 & 45.2 \\
\hline & Private employee & 33 & 8.9 \\
\hline & Government employee & 68 & 18.3 \\
\hline & Merchant & 29 & 7.8 \\
\hline & Farmer & 56 & 15.1 \\
\hline & Student & 18 & 4.8 \\
\hline \multirow[t]{2}{*}{ Residential area } & Urban & 242 & 65.1 \\
\hline & Rural & 130 & 34.9 \\
\hline
\end{tabular}




\section{Patient -related factors}

From this study, one hundred sixty (43\%) participants were priemigravida. Of the 372 women, $74.5 \%$ had emergency surgery while $25.5 \%$ of the women undergone elective surgery. A significant percentage $88.7 \%$ and $72.3 \%$ of participants had no previous medical and surgical history respectively. Two hundred and twelve (57\%) of the respondents were dissatisfied with the explanation given to them before the surgery and informed consent. The overall practice of informed consent was poor which accounts for $63.7 \%$ of the study. (Table 2).

Table 2

Patient-related factors of knowledge towards informed consent at Jimma Medical Center, Jimma, Ethiopia 2020.

\begin{tabular}{|c|c|c|c|}
\hline Variable & Category & Frequency & Percent \\
\hline \multirow[t]{4}{*}{ Parity } & Null Para & 14 & 3.8 \\
\hline & Premigravida & 160 & 43.0 \\
\hline & Multigravida & 150 & 40.3 \\
\hline & Grand multipara & 48 & 12.9 \\
\hline \multirow[t]{2}{*}{ Type of surgery } & Elective & 95 & 25.5 \\
\hline & Emergency & 277 & 74.5 \\
\hline \multirow{2}{*}{$\begin{array}{l}\text { Previous medical } \\
\text { history }\end{array}$} & Yes & 42 & 11.3 \\
\hline & No & 330 & 88.7 \\
\hline \multirow{2}{*}{$\begin{array}{l}\text { Previous surgical } \\
\text { history }\end{array}$} & Yes & 103 & 27.7 \\
\hline & No & 269 & 72.3 \\
\hline \multirow{2}{*}{$\begin{array}{l}\text { Number of operation } \\
\text { done }\end{array}$} & 1 & 60 & 58.3 \\
\hline & $\geq 2$ & 43 & 41.7 \\
\hline \multirow[t]{2}{*}{ Satisfaction } & Dissatisfied & 212 & 57.0 \\
\hline & Satisfied & 160 & 43.0 \\
\hline \multirow[t]{2}{*}{ Practice } & Poor & 237 & 63.7 \\
\hline & Good & 135 & 36.3 \\
\hline
\end{tabular}

\section{Respondents' knowledge on informed consent}


Table 3

Respondents' knowledge towards informed consent at Jimma Medical Center, Jimma, Ethiopia 2020.

\begin{tabular}{|c|c|c|}
\hline \multirow[t]{2}{*}{ Questioners } & \multicolumn{2}{|c|}{ Frequency \& Percentage } \\
\hline & Yes & No \\
\hline Signing the consent form is a legal requirement. & $268(72 \%)$ & $104(28 \%)$ \\
\hline Signing the consent form does remove your right to Compensation. & $216(58.1 \%)$ & $156(41.9 \%)$ \\
\hline Have the right to change your mind after signing consent? & $\begin{array}{l}74 \\
9(19.9 \%)\end{array}$ & $298(80.1 \%)$ \\
\hline If you are not able to sign the consent form, the operation couldn't do? & $285(76.6 \%)$ & $87(23.4 \%)$ \\
\hline $\begin{array}{l}\text { If you refuse to sign the consent form, the operation couldn't do even } \\
\text { you die? }\end{array}$ & $293(78.8 \%)$ & $79(21.2 \%)$ \\
\hline $\begin{array}{l}\text { If you can't sign the consent form, your next of kin can sign on your } \\
\text { behalf? }\end{array}$ & $319(85 \%)$ & $53(14.2 \%)$ \\
\hline $\begin{array}{l}\text { After consent, the doctor can do anything different from what was on } \\
\text { the form as s/he wants? }\end{array}$ & $289(77.7 \%)$ & $83(22.3 \%)$ \\
\hline $\begin{array}{l}\text { A Doctor cannot do anything different from what was on the form } \\
\text { unless it is lifesaving? }\end{array}$ & $342(91.9 \%)$ & $30(8.1 \%)$ \\
\hline
\end{tabular}

In this study, the respondents had overall knowledge of surgical informed consent $287(77.2 \%(95 \% \mathrm{Cl}$ : 72.8-81.2)) and $22.8 \%$, poor knowledge, and good knowledge respectively.

\section{Service- related factors}

In this study, $92.2 \%$ of the respondents given insufficient time to decide the procedure, and the majority of respondents 220 the mode of decision-making were self-method of decision. The majority (81.2\%) participants reported having received SIC counseling from resident physicians, the remaining got from obstetrician-gynecologists 44(11.8\%) and nurse-midwives 26(7\%). (Table 4) 
Table 4

Service related factors of patient's knowledge at Jimma Medical Center, Jimma, Ethiopia 2020.

\begin{tabular}{|c|c|c|c|}
\hline Variable & Category & Frequency & Percent \\
\hline \multirow{2}{*}{$\begin{array}{l}\text { Is consent form written with mother } \\
\text { tongue }\end{array}$} & Yes & 234 & 62.9 \\
\hline & No & 124 & 33.3 \\
\hline \multirow[t]{3}{*}{ Consent requested by } & Ob-gyn specialist & 44 & 11.8 \\
\hline & General practitioner/resident & 302 & 81.2 \\
\hline & Midwife/nurse & 26 & 7.0 \\
\hline \multirow[t]{4}{*}{ Timing of consent } & $\begin{array}{l}\text { The day before the date of } \\
\text { surgery }\end{array}$ & 65 & 17.5 \\
\hline & On the day of surgery & 87 & 23.4 \\
\hline & Immediately before surgery & 208 & 55.9 \\
\hline & On the operation table & 12 & 3.2 \\
\hline \multirow[t]{3}{*}{ Time taken to provide informed consent } & $<5$ minute & 231 & 62.1 \\
\hline & $5-10$ minute & 76 & 20.4 \\
\hline & $>10$ minute & 65 & 17.5 \\
\hline \multirow[t]{2}{*}{ Timing taken to decision making } & Early & 343 & 92.2 \\
\hline & Delay & 29 & 7.8 \\
\hline \multirow[t]{3}{*}{ Decision making's mode } & Self & 220 & 59.1 \\
\hline & Share & 94 & 25.3 \\
\hline & Paternalism & 58 & 15.6 \\
\hline
\end{tabular}

Below half $179(48 \%)$ of study participants had a good relationship to health care provides while 193(52\%) study participants had e poor relationship with healthcare providers (figure 2).

\section{Factors associated with knowledge of surgical informed consent}

The association between independent variables and dependent variables (outcome) was analyzed using a binary logistic regression model. In bivariate analysis factors like age, educational status, marital status, residence, schedule of surgery, satisfaction level, and patient-healthcare provider relationship were significant at $p$-value $<0.25$. Those candidate variables in bivariate analysis were transported to multivariate logistic regression. Finally; Education, satisfaction level, and patient healthcare provider 
relationship were found factors associated with knowledge regarding surgical informed consent in multivariate analysis $(P<0.05)$ (Table 5).

In this study, Patients who were educated(literate) had 1.22 times more likely knowledgeable regarding surgical informed consent than illiterate patients (AOR: 1.22 (95\% Cl: 1.1-2.47). Satisfied patients had 1.8 times more knowledgeable regarding surgical informed consent than dissatisfied patients did (AOR:

1.823(95\% Cl: 1.061-3.134). Those Patients who had poor relationships with health care providers had $47.2 \%$ less likely knowledgeable than their counterparts (AOR: $0.472(95 \% \mathrm{Cl}: 0.271-0.822)$. 
Table 5

-Shows Results of the bi-variable and multivariable logistic regression analysis of associated factors of patient knowledge towards surgical informed consent for surgical procedures at Jimma Medical Center, Jimma, Ethiopia /2020.

\begin{tabular}{|c|c|c|c|c|c|c|c|}
\hline \multirow[t]{2}{*}{ Variable } & \multirow[t]{2}{*}{ Category } & \multicolumn{2}{|c|}{ Knowledge } & \multirow[t]{2}{*}{ COR } & \multirow{2}{*}{$\begin{array}{l}\mathrm{p} \text { - } \\
\text { value }\end{array}$} & \multirow[t]{2}{*}{ AOR } & \multirow{2}{*}{$\begin{array}{l}\mathrm{p}- \\
\text { value }\end{array}$} \\
\hline & & Good & Poor & & & & \\
\hline \multirow[t]{2}{*}{ Age } & $<35$ & 69 & 255 & 1 & & 1 & \\
\hline & $>35$ & 16 & 32 & $\begin{array}{l}1.848(.958- \\
3.562)\end{array}$ & .067 & & \\
\hline \multirow[t]{2}{*}{ Educational status } & Illiterate & 15 & 66 & 1 & & 1 & \\
\hline & Literate & 70 & 221 & $\begin{array}{l}1.394(.748- \\
2.595)\end{array}$ & .205 & $\begin{array}{l}1.22(1.1- \\
2.47)\end{array}$ & $0.045^{\star}$ \\
\hline \multirow[t]{2}{*}{ Marital status } & Single & 19 & 43 & 1 & & 1 & \\
\hline & Married & 66 & 244 & $\begin{array}{l}.612(.334- \\
1.121)\end{array}$ & .112 & & \\
\hline \multirow[t]{2}{*}{ Residence } & Urban & 61 & 181 & 1 & & 1 & \\
\hline & Rural & 24 & 106 & $\begin{array}{l}.672(.396- \\
1.141)\end{array}$ & .141 & & \\
\hline \multirow[t]{2}{*}{ Schedule of surgery } & Elective & 26 & 69 & 1 & & 1 & \\
\hline & Emergency & 59 & 218 & $\begin{array}{l}.718(.421- \\
1.226)\end{array}$ & .225 & & \\
\hline \multirow[t]{2}{*}{ Satisfaction level } & Dissatisfied & 43 & 169 & 1 & & 1 & \\
\hline & Satisfied & 42 & 118 & $\begin{array}{l}1.399 \\
(.861- \\
2.274)\end{array}$ & .176 & $\begin{array}{l}1.823 \\
(1.061- \\
3.134)\end{array}$ & $.003^{*}$ \\
\hline \multirow{2}{*}{$\begin{array}{l}\text { Patient-healthcare } \\
\text { provider } \mathrm{r} / \mathrm{n}\end{array}$} & Poor & 51 & 142 & 1 & & 1 & \\
\hline & Good & 34 & 145 & $\begin{array}{l}.653(.399- \\
1.068)\end{array}$ & .089 & $\begin{array}{l}.472 \\
(.271-.822)\end{array}$ & $.008^{*}$ \\
\hline
\end{tabular}

NB. 1 = considered as reference categories

\section{Discussion}

This Crossectional study was carried out to determine the level of knowledge towards surgical informed consent and the factors associated among patient underwent obstetrics and gynecologic surgery. This study shows that there was a significantly low(poor) level of knowledge $77.2 \%(95 \% \mathrm{Cl}: 72.8-81.2)$ towards informed surgical consent, was similar to the crossectional study conducted at Cairo University Hospital, 
Egypt where $72.7 \%$ of participants had a poor level of knowledge regarding surgical informed consent (8).

However, the result of our study was lower than the studies conducted at Rwanda 83\%(7)and St. Paul's Hospital Millennium Medical College, Ethiopia(11) only 40(10.5\%) had a good level and $89.5 \%$ (14)participants had poor level of knowledge regarding surgical informed consent.

The discrepancy from a study done in Rwanda(7)might be the difference in the study setting sample size and inclusion criteria differences where study in Rwandahad only (147) participants and the study involves participants from all the surgical departments (general surgery, orthopedic, obstetrics, and gynecology, urology, ENT, maxilla facial and plastic surgery stratum). The possible explanation for discrepancy from a study done at St. Paul's Hospital Millennium Medical College, Ethiopia(11)may be the difference in sociodemographic variation and inclusion criteria of participants, the study was done in St. Paul's Hospital Millennium Medical College includes all adults both male and female, but our study involves only on women who undergone gynecologic and obstetrics surgery.

Our study findings Higher than the cross-sectional studies conducted at a dental hospital in rural Haryana, India17 \%( (15), at Istanbul University, Turk 38.1\% (9) and at Aminu Kano, Nigeria $2.5 \%$ (16) participants had an poor level of an overall knowledge regarding surgical informed consent. The possible explanation for the difference between our study and the study conducted at a dental hospital in rural Haryana, India (15) might be the difference in the study setting, socio- demographic variation, and inclusion criteria among participants. The study conducted in India involves the both male and female participants but our study involves only female participants.

Our study result was different from the study done at Istanbul University, Turk,38.1\% (9)this difference might be the difference in the study setting and sample size, in Istanbul, Turk only one hundred two 102 patients were involved. Our finding was also different from the study done in Nigeria(16)this may be because of socio- demographic variation and service provision difference between Ethiopia and Nigeria. Sample size difference; only Three hundred and ninety- eight (398) women were recruited for the study conducted in Nigeria.

Our study also revealed that Patient's knowledge of surgical informed consent was associated with patients' satisfaction, patient health care provider relationship, and educational status. In this study, knowledge towards surgical informed consent was significantly higher in literate patients. Patients who were educated (literate) had 1.22 times more knowledgeable regarding surgical informed consent than illiterate patients (AOR: 1.22 (95\% Cl: 1.1-2.47). This result was supported by studies conducted at rural Haryana, India(15), Kano, Nigeria(16), Rwanda(7), public Hospitals in Khartoum State, Sudan(17), and at St. Paul's Hospital Millennium Medical College, Ethiopia(11). The possible reason might be that educated patient's more likely struggle for obtaining adequate information on the understanding of procedures during a consent process (18). Moreover, during the time of briefing educated patients could join the process actively and understand what was told than patients who were illiterates. In addition, their level of awareness might be high than their counterparts and educated patients are conscious of their rights 
and are more likely to understand and comprehend information on consent than uneducated individuals who are more likely to linger overon mystic beliefs.

In addition, The current study revealed that a higher professional and patient relationship experience was associated with knowledge of informed surgical consent, those Patients who had poor relationships with health care providers had $47.2 \%$ less likely knowledgeable than their counterparts (AOR: $0.472(95 \% \mathrm{Cl}$ : $0.271-0.822$ ). This was supported by the other study conducted at Lowa City, lowa (19) and a systematic review on patient and doctor relationship (20). This is the fact shared decision-making improves the caregiver/patient relationship and integrates the patient as an actor in his care. It also modifies the patient/physician relationship in the surgical field (21).

Additionally patient satisfaction level of the surgical informed consent process had an association with knowledge regarding surgical informed consent, satisfied patients had 1.8 times more knowledgeable regarding surgical informed consent than dis satisfied patients did (AOR: 1.823(95\%Cl: 1.061-3.134). This is similar to the studies conducted at spin clinic German university hospital(22) and American college of rheumatology(23). This may be due to Patients have a higher satisfaction if the consent was read and understood by the patients. Preoperatively, patients satisfied with the consent process may have a better recall of the risks/benefits.

Generally, our study declares that knowledge of surgical informed consent, increases satisfaction and good patient health care relation with the consent process for surgical procedures. Positively associated with patient's satisfaction and patient-health care provider relationship with the consent process for surgical procedures

\section{Conclusion}

Knowledge of the patient's towards informed consent for their obstetric and gynecologic surgical procedure was significantly poor in this study and Surgeons spend less time with their patients explaining the procedure. Factors like patient health care provider relationship, education, and satisfaction level were associated with knowledge towards surgical informed consent for surgical procedures. The hospital needs to design awareness creation measures towards surgical informed consent (SIC).

Adequate information should be given to the patient orally and in writing during hospitalization to improve knowledge towards surgical informed consent. Healthcare professionals need to be bonding more information calls during hospitalization. Towards informed consent for obstetric and gynecologic surgical procedures, surgeons should make out adequate time to explain surgical procedures and possible complications to patients before any surgical procedure. To ensure less apprehension consent should be discussed with patients several days before surgery so that patients.

Health care providers must empower patients to have more information and help to make decisions regarding their health particularly during points of additional stress such as a new diagnosis and treatment plan. In general, more information on patients' knowledge regarding surgical informed consent 
before to surgical procedure is needed to provide adequate input on ways to improve the consent process to make it better suited to fit the needs of all patients

\section{Limitation Of The Study}

The possible limitations of the study: both emergency and elective obstetrics and gynecologic patients were included. Emergency surgery respondents probably would be less informed than elective patients considering the stress involved and time constraints in emergency procedures. Clients often rush into surgery before discussing the issue with family and friends. Previous studies have found that clients undergoing elective surgeries, which afford them enough time to make informed decisions achieve a better understanding of proposed treatments compared with clients undergoing emergency surgeries, where there is little or no time for a lengthy discussion.

\section{Abbreviations}

Cl: Confidence interval, COR: Crude Odds Ratio, JMC: Jimma medical center, OR: Odds Ratio,

PDRQ: Patient- Doctor Relationship Questioner, SD: Standard Deviation, SIC Surgical Informed Consent.

\section{Declarations}

\section{Ethical approval and consent to participate}

Ethical clearance was obtained from a Research Ethics Committee of College of Health Sciences, Jimma University. The permission and agreement consent was taken from Jimma Medical Center. Before the start of data collection, all participants received both oral and written information about the study and gave their written informed consent to participate. To keep the confidentiality names and medical record numbers of the participant were not registered in the data collection tool. Generally, the study was performed per the Declaration of Helsinki.

\section{Consent for publication}

Not applicable

\section{Availability of data and materials}

The datasets are obtained from the corresponding author upon reasonable request

\section{Competing interests}

The authors declared, as there is no competing interest

\section{Funding}


There is no funding for this research.

\section{Authors' contributions}

Author's contributions: All authors contributed to the study conception and design. BT drafted the manuscript. While AY and TB haves critically reviewed the draft for the intellect and rewritten the entire manuscript the way it is currently presented. All authors had approved the final version.

\section{ACKNOWLEDGEMENTS}

We would like to acknowledge Jimma University, Jimma medical center staff, data collectors, supervisor, and patients for their co-operation during the data collection period.

\section{References}

1. Bhute A. Informed Consent in Obstetrics and Gynecology. Indian Scenario. 2019;3(June 2017):6771.

2. Lennox A. HOW CAN WE IMPROVE INFORMED CONSENT PROCESSES ? 2019;(May).

3. Erkan I, Mayadagli Y, Akbaba M. Assessment of patients' knowledge level regarding informed consent from the ethical aspect. 2017.

4. Teshome M, Wolde Z, Gedefaw A, Tariku M, Asefa A. Surgical informed consent in obstetric and gynecologic surgeries: experience from a comprehensive teaching hospital in Southern Ethiopia. 2018;1-9.

5. Hammami MM, Al-gaai EA, Al-jawarneh Y, Amer H, Hammami MB, Eissa A, et al. Patients ' perceived purpose of clinical informed consent: Mill's 's individual autonomy model is preferred. 2014;3354(Mbc 03).

6. Tejaswi VP, Dongare A, Hegde P, Patil GL, Shridevi AS, Anitha S. Exploring the adequacy of informed consent for caesarean section at a tertiary care center. 2020;9(12):4878-82.

7. Mbonera F, Chironda $G$. The relationship between knowledge and perception of patients regarding informed consent in surgical procedures in Rwanda. 2018;6(2):408-16.

8. Galal YS. Knowledge, practice, and perception towards the informed consent process among physicians and patients in General Surgical Departments at Cairo University Hospitals Subjects \&. Methods. 2016;34(2):1-17.

9. Profile SEE. Assessment of patients' knowledge level regarding informed consent from the ethical aspect. 2019;(April 2017).

10. Viegas K, Caregnato R. Surgical patients ' understanding of the free and informed consent form Termo de consentimento informado: entendimento do paciente cirúrgico. 2021;(January 2016).

11. Surgery OA. Knowledge and Perception of Ethiopian Surgical Patients to Informed Consent Practice for Surgical Procedures. 2020;0-5. 
12. Sulaiman Al, Ayyuba R, Diggol IG, Haruna IU. Knowledge, attitude, and perception of patients towards informed consent in obstetric surgical procedures at Aminu Kano Teaching Hospital. 2020;(June).

13. Convie LJ, Carson E, Mccusker D, Mccain RS, Mckinley N, Campbell WJ, et al. The patient and clinician experience of informed consent for surgery: a systematic review of the qualitative evidence. 2020;1-17.

14. Hospital T. Patient satisfaction with the perioperative surgical services and associated factors at a University Referral and Teaching Hospital, 2014: a cross-sectional study. 2017;8688:1-14.

15. Singh A. A cross -sectional study of the patient's awareness and understanding of toward legal nature of informed consent in a dental hospital in rural Haryana. 2012;2(1):2012-4.

16. Sulaiman Al, Ayyuba R, Diggol IG, Haruna IU. Knowledge, attitude, and perception of patients towards informed consent in obstetric surgical procedures at. Aminu Kano Teaching Hospital. 2015;12(1):45-50.

17. Akasha RA, Beshir L, El-Fadefadul M. Mapping the Quality of Informed Consent for Major Surgical Procedures in Public Dental Hospitals in Khartoum State, Sudan, 2017: A Cross- Sectional Study. 2018;8(11):1-7.

18. Keim-Mmalpass J. Health literacy and informed consent for clinical trials: a systematic review and implications for nurses. 2019;(July).

19. Xu J, Prince AER, City I. Shared decision-making in vascular surgery. J Vasc Surg [Internet]. 2019;70(5):1711-5. Available from: https://doi.org/10.1016/j.jvs.2019.03.002.

20. Chandra S. iMedPub Journals Trust and Communication in a Doctor- Patient Relationship: A Literature Review Abstract Literature Review - Trust and Communication Trust in the doctor-patient relationship. 2018;1-6.

21. Code F, Health P. From informed consent to shared decision-making in surgery. 2019;181-4.

22. Weckbach S, Kocak T, Reichel H, Lattig F. A survey on patients ' knowledge and expectations during informed consent for spinal surgery: can we improve the shared decision-making process ? Patient Saf Surg [Internet]. 2016;10-3. Available from: http://dx.doi.org/10.1186/s13037-016-0103-z.

23. Johnson MR, Singh JA, Stewart T, Gioe TJ. Patient Understanding and Satisfaction in Informed Consent for Total Knee Arthroplasty: A Randomized Study. 2011;63(7):1048-54.

\section{Figures}




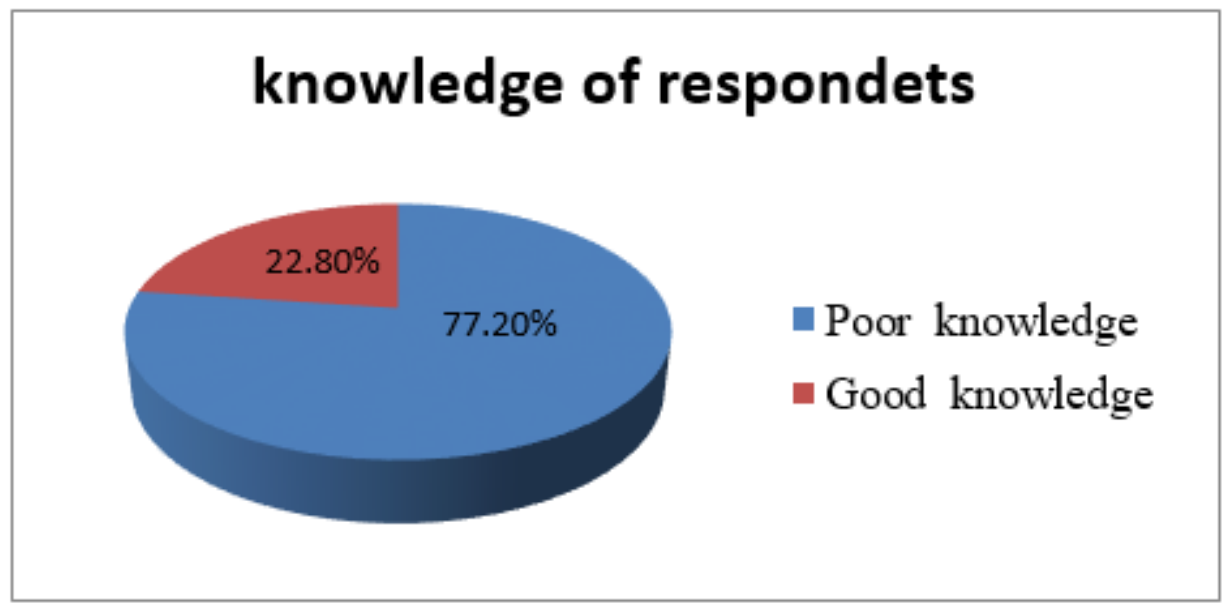

\section{Figure 1}

Displays the patient's level of knowledge towards informed consent for surgical procedures at Jimma Medical Center, Jimma, Ethiopia 2020.

\section{Patient-healthcare providers relationship}

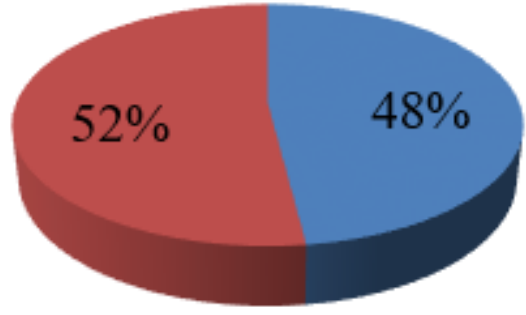

Good relationship

Poor relation ship

Figure 2

patient-health care providers' relationship at Jimma Medical Center, Jimma, Ethiopia 2020. 